The Rocks of THE Moon.-M. Landerer, in continuation of his memoir last year on the polarizing angle of the lunar surface, has just communicated to the Paris Academy the re sults of some determinations of the angle of polarization of igneous rocks. He finds that specimens from different localities give practically identical results, the probable errors never being greater than $\pm 5^{\prime}$. The polarizing angle increases from $30^{\circ} 5^{\prime}$ for ophite, through syenite, basalt $\left(31^{\circ} 43^{\prime}\right)$, serpentine, trachyte, granite $\left(32^{\circ} 20^{\prime}\right)$, diorite, diabase, andesite $\left(32^{\circ} 50^{\prime}\right)$, to obsidian $\left(33^{\circ} 46^{\prime}\right)$. Vitrophyre, a black rock from the Rhodope chain, which contains large crystals of sanidine, magnetite, and hornblende, in a fluidal, non-perlitic matrix, has a polarizing angle of $33^{\circ} 18^{\prime}$, which approximates very closely to that of the lunar surface. Without presuming too much on this result, the author regards it as at any rate an additional proof of the similarity, and therefore common origin, of our earth and its satellite. The fact that the polarizing angle of ice is more than $37^{\circ}$, is another objection to M. Hirn's hypothesis of Iunar glaciation.

BRooks's COMET ( $a$ I 890).-Dr. Bidschof gives the following ephemeris in Astronomische Nachrichten, No. 2979 :- -

\begin{tabular}{|c|c|c|c|c|c|c|}
\hline \multicolumn{7}{|c|}{ Ephemeris for Berin Midnight. } \\
\hline $\mathbf{x} 890$. & R.A. & & Decl. & $\log r$ & $\quad \log \Delta$ & $\begin{array}{l}\text { Bright- } \\
\text { ness. }\end{array}$ \\
\hline I...I3 & II & & +45379 & $0.312 I$ & & .. $1 \cdot 38$ \\
\hline $5 \ldots 13$ & 7 & & & ... 0.3160 & & ... I'27 \\
\hline .13 & 5 & & 42242 & $\ldots 0 \cdot 3200$ & .. 0.3978 & $\ldots \mathrm{I} \cdot 18$ \\
\hline $13 \ldots 13$ & 3 & 9 & 4056.5 & $\ldots 0 \cdot 3242$ & $\ldots 0.4100$ & ... I'09 \\
\hline & & 45 & 3934.5 & $\ldots 0 \cdot 3285$ & $\ldots 0.4215$ & $\ldots \quad \mathrm{I} \cdot \mathrm{O} 2$ \\
\hline $21 \ldots 13$ & & & $3^{8} \quad 17 \%$ & .. 0.3330 & 0.4323 & .. 0.95 \\
\hline $25 \ldots 13$ & 0 & $12 \ldots$ & & $\ldots 0.3376$ & 0.4423 & $\ldots 0.89$ \\
\hline $29 \ldots 12$ & 259 & $5^{8} \ldots$ & $3558 \cdot 6$ & $\ldots 0.3422$ & 0.4517 & ... 0.83 \\
\hline$p t .2 \ldots$ I' & & & $3456 \cdot$ I & $\ldots 0.3470$ & $\ldots 044605$ & $\ldots 0.78$ \\
\hline
\end{tabular}

The brightness on March $2 \mathbf{I}$ has been taken as unity.

BroRsen's COMET.-Mr. E. Barnard, of Lick Observatory, notes, in the above number of Astronomische Nachrichten, that he has made many searches for this comet from December of last year to the end of April, but with only a negative result He notes that during the search he has found several unrecorded nebulæ.

Two New Comers ( $b$ and $c$ I89o).-M. Coggia, at Marseilles, has discovered a pretty bright comet having the following positions (Astronomische Nachrichten, 2980).

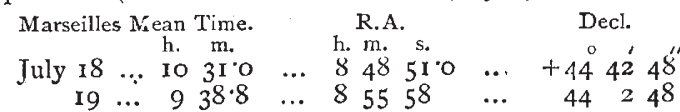

Mr. Denning discovered a faint comet at Britol on July 2.3 ; its position at I 3 hours Greenwich mean time being R.A. I 5 h. $12 \mathrm{~m}$., and Decl. $+78^{\circ}$. It was moving towards the east (Edinburgh Circular, No. 8).

A New. Asteroid 294.-M. Charlois, of Nice Observatory, discovered an asteroid of the twelfth magnitude on the 15 th inst.

\section{THE SCIENTIFIC PRINCIPLES INVOLVED IN MAKING BIG GUNS.}

II.

Part II.-The Strains in The Gun.

(29) $\mathrm{S} O$ far we have dealt only with the stresses in the metal, and we have determined these stresses in the manner given by Rankine in his "Applied Mechanics," $\$ 273$, p. 290, in which the only assumption made is that the metal of each cylinder is homogeneous. But when the gun-maker wishes to set up a given pressure of shrinkage between two cylinders, he has to determine, by calculation or experiment, the slight amount by which, when cold, the external radius of one cylinder must exceed the internal raouius of the next cylinder which is shrunk on it; the outer cylinder being expanded by heat and slipped on, in order that the given initial pressure may be set up on the cooling of the outer cylinder; and this, too, when other cylinders are shrunk on afterwards.

We must therefore determine the strains and deformations set up in a given cylinder due to given applied pressures, and thus we require the equations giving the strains due to given applied

NO. $108_{3}$, VOL. 42$]$ stresses when the coefficients of elasticity of the metal are known.

(30) Now, it is proved in Thomson and Tait's "Natural Philosophy," $\S 882,683$, for a substance of which $k$ is the elasticity of volume or bulk-modulus, and $n$ is the elasticity of figure or rigidity, that when the stress is a simple longitudinal tension $\mathrm{P}$, the principal strains in the substance are an extension $\mathrm{P}\left(\frac{\mathbf{I}}{3^{n}}+\frac{\mathbf{I}}{9 k}\right)$ in the direction of the tension, and a compression $\mathrm{P}\left(\frac{\mathrm{I}}{6 n}-\frac{\mathrm{I}}{9^{k}}\right)$ in all directions perpendicular to the tension.

We use the words tension and pressure, as before, to denote stresses measured in terms of pull or thrust per unit area, with our practical units, measured in tons per square inch; while the words extension and compression are used (in accordance with the terminology of Maxwell, Everett, and Unwin) to mean the strains, measured by the ratio of linear elongation or contraction to the original length.

Thus, the tension or pressure being the stress, the extension or compression is the corresponding strain; and Hooke's law of elasticity (ut tensio sic vis), translated into a formula, gives $\frac{\text { stress }}{\text { strain }}=\frac{\text { tension }}{\text { extension }}=\frac{\text { pressure }}{\text { compression }}=$ the modulus of elasticity.

(3I) Then, by superposition, if $e, f, g$ are the extensions produced in three rectangular directions by tensions $P, Q, R$ in these directions-

$$
e=\left(\frac{\mathbf{I}}{3 n}+\frac{\mathbf{I}}{9 k}\right) \mathrm{P}-\left(\frac{\mathbf{I}}{6 n}-\frac{\mathbf{I}}{9 k}\right)(\mathrm{Q}+\mathrm{R}), \ldots(3 \mathrm{I})
$$

with two similar expressions for $f$ and $g$; or, in Thomson and Tait's notation, § 694-

$$
\begin{aligned}
& \mathrm{M} e=\mathrm{P}-\sigma(\mathrm{Q}+\mathrm{R}), \ldots .(32) \\
& \mathrm{M} f=\mathrm{Q}-\sigma(\mathrm{R}+\mathrm{P}), \ldots .(33) \\
& \mathrm{M} g=\mathrm{R}-\sigma(\mathrm{P}+\mathrm{Q}), \ldots . .(34)
\end{aligned}
$$

where

$$
\frac{\mathbf{I}}{\mathrm{M}}=\frac{\mathbf{I}}{3^{n}}+\frac{\mathrm{I}}{9^{k}} \text {, or } \mathrm{M}=\frac{9 n k}{3^{k+n}},
$$

so that $\mathrm{M}$ is Young's modulus of elasticity, the modulus which is directly observable when a test-piece of the substance (steel) is placed in a testing-machine, and the ratio $\mathrm{M}=\mathrm{P} / \mathrm{e}$ is observed of $\mathrm{P}$, the tension, to $e$, the extension, no lateral tension being applied, or

also,

$$
\begin{aligned}
& \mathrm{Q}=\mathrm{o}, \mathrm{R}=0 ; \\
& \sigma=\frac{3 k-2 n}{6 k+2 n},
\end{aligned}
$$

called Poisson's ratio, is the ratio of the lateral compression to the linear extension of the substance when the stress is a simple tension.

(32) Again, by independent investigation, as in $\S 692$, or by solution of the preceding equations $\left(3^{2}, 33,34\right)$, we find-

$$
\begin{aligned}
& \mathrm{P}=\left(k+\frac{4}{3} n\right) e+\left(k-\frac{2}{3} n\right)(f+g), \\
& \mathrm{Q}=\left(k+\frac{4}{3} n\right) f+\left(k-\frac{2}{3} n\right)(\delta+e) \\
& \mathrm{R}=\left(k+\frac{4}{3} n\right) g+\left(k-\frac{2}{3} n\right)(e+f) ;
\end{aligned}
$$

or, in Lamé's notation ("Théorie de l'Élasticité," § 19)-

$$
\begin{aligned}
& \mathrm{P}=\lambda \theta+2 \mu \epsilon, \\
& \mathrm{Q}=\lambda \theta+2 \mu f, \\
& \mathrm{R}=\lambda \theta+2 \mu g, \\
& \theta=a+b+c,
\end{aligned}
$$

with

the cubical expansion; and

$$
\lambda=k-\frac{2}{3} n, \mu=n .
$$

The above equations show that when the strain is given as a simple uniform longitudinal extension $e$, the stresses consist of a uniform longitudinal tension, $\left(k+\frac{4}{3} n\right) e=(\lambda+2 \mu) e$, in the direc- 
tion of the strain, and of uniform lateral tension, $\left(k-\frac{2}{3} n\right) e=\lambda e$, in every direction perpendicular to the strain.

(33) These equations, and the previous equations, which show that, when the stress is a simple uniform longitudinal tension $P$, the strains consist of a uniform extension $\mathrm{P} / \mathrm{M}$ in the direction of the tension, and of uniform lateral compression $\sigma \mathrm{P} / \mathrm{M}$ perpendicular to the tension, are so fundamental in the theory of the elasticity of isotropic bodies, that we are almost tempted to make a digression here on their proof, in the manner given in Thomson and Tait's "Natural Philosophy," $\$ \$ 682,683$, and 692.

It is necessary to describe and compare the notations carefully, for subsequent purposes, as the variety of notation in the subject of elasticity is very confusing.

(34) Applying these principles to the gun, we take the three principal directions of stress and strain, as (i.) circumferentially to the gun, (ii.) radially, (iii.) longitudinally; and now, estimating tensions and extensions as positive, we have-

$$
\begin{aligned}
& \mathrm{P}=\quad t=a r^{-2}-b, \\
& \mathrm{Q}=-p=-a r^{-2}-b ;
\end{aligned}
$$

while the value of $\mathrm{R}$ is still indeterminate.

For the determination of the strains, we denote by $u$ the increase of radius, $r$, of a circumferential fibre; and then $2 \pi z$ being the elongation of the fibre of original length $2 \pi r$, the circumferential extension

$$
e=2 \pi u / 2 \pi r=u / r
$$

while the radial extension $f=d u / d r$; the Iongitudinal extension $s$ being as yet undetermined.

(35) Expressing the strains $e$ and $f$ in terms of the longitudinal tension $\mathrm{R}$,

$$
\begin{aligned}
\mathrm{M} e & =\mathrm{M} u / r=\mathrm{P}-\sigma(\mathrm{Q}+\mathrm{R}) \\
\quad & =a r^{2}-b+\sigma\left(a r^{-2}+b\right)-\sigma \mathrm{R} \\
\quad & =(\mathrm{I}+\sigma) a r^{2}-(\mathrm{I}-\sigma) b-\sigma \mathrm{R} ;
\end{aligned}
$$$$
\mathbf{M u}=(\mathrm{I}+\sigma) a r-1-(\mathrm{I}-\sigma) b r-\sigma \mathrm{R} r ; \ldots(38)
$$

so that, differentiating with respect to $r$,

$$
\begin{aligned}
\mathbf{M} f & =\mathbf{M} d u / d r \\
& =-(\mathbf{I}+\sigma) a r^{-2}-(\mathbf{I}-\sigma) b-\sigma d(\mathrm{R} r) / d r \\
& =Q-\sigma \mathbf{P}-\sigma d(\mathbf{R} r) / d r .
\end{aligned}
$$

$$
\mathrm{M} f=\mathrm{Q}-\sigma(\mathrm{R}+\mathrm{P}),
$$

Barlow, Lamé, and Hart's expressions for the stresses are verified, provided that

$$
d(\mathrm{R} r) / d r=\mathrm{R}
$$

$$
d \mathrm{R} / d r=\mathrm{o}, \quad \mathrm{R}=\text { constant. }
$$

(36) On the other hand, expressing the strains $e$ and $f$ in terms of the longitudinal strain or extension $g$, since

$$
\begin{aligned}
\mathrm{R} & =\sigma(\mathrm{P}+\mathrm{Q})+\mathrm{M} g \\
\mathrm{M} e & =\mathrm{M} u / r=\mathrm{P}-\sigma(\mathrm{Q}+\mathrm{R}) \\
& =\left(\mathbf{I}-\sigma^{2}\right) \mathrm{P}-\sigma(\mathbf{I}+\sigma) \mathrm{Q}-\sigma \mathrm{M} g \\
& =\left(\mathbf{I}-\sigma^{2}\right)\left(\mathrm{P}-\sigma^{\prime} \mathrm{Q}\right)-\sigma \mathrm{M} g,
\end{aligned}
$$

putting

so that

$$
\sigma^{\prime}=\frac{\sigma}{\mathrm{I}-\sigma}
$$

$\mathrm{M} u=\left(\mathrm{I}-\sigma^{2}\right)\left\{\left(\mathrm{I}+\sigma^{\prime}\right) a r^{-1}-\left(\mathrm{I}-\sigma^{\prime}\right) b r\right\}-\sigma \mathrm{Mg}_{\mathrm{S}} ; \cdot\left(3^{*}\right)$ and differentiating with respect to $r$,

$$
\begin{aligned}
\mathrm{M} f & =\mathrm{M} d u / d r \\
& =\left(\mathrm{I}-\sigma^{2}\right)\left(\mathrm{Q}-\sigma^{\prime} \mathrm{P}\right)-\sigma \mathrm{M} d(g r) / d r,
\end{aligned}
$$

agreeing again in giving

provided that

$$
\mathrm{M} f=\mathrm{Q}-\sigma(\mathrm{R}+\mathrm{P},
$$

or

$$
d(g r) / d r=g ;
$$

\footnotetext{
$$
d g / d r=0, \quad g=\text { constant. }
$$
}

We have proved, then, that either the longitudinal tension $\mathrm{R}$ or the longitudinal extension $g$ of the gun must be uniform, for the values of the stresses given by the formulas of Barlow, Lamé, Hunt, and Rankine, to be strictly accurate ; we shall follow the ordinary practice in assuming that $\mathrm{R}$ is uniform, but the work will be almost precisely the same if we assume that $g$ is uniform (Prof. P. G. Tait, "On the Accurate Measurement of High Pressures," Proc. R.S. Edinburgh, I879-80).

(37) Now, let us determine, for the simplest case of the tube $\mathrm{A}$ and the jacket $\mathrm{B}$, the requisite shrinkage for producing a given initial pressure $\widetilde{\omega}_{o}=p_{i}$ at their common surface; the shrinkage, denoted by $\mathrm{S}$, being defined as the excess of the outside diameter $2 \rho_{o}$ of the tube $A$ over the inside diameter $2 r_{i}$ of the jacket $\mathrm{B}$, when both are finished cold in the lathe; so that

$$
\frac{1}{2} \mathrm{~S}=\rho_{\circ}-r_{i} \text {. }
$$

The jacket $B$ is now expanded by heat till its inside diameter is greater than $2 \rho_{o}$, and then slipped over the tube $\Lambda$; on cooling, the jacket $\mathrm{B}$ shrinks and grips the tube $\Lambda$ with the requisite pressure, $p_{i}=\widetilde{\omega}_{0}$.

Taking the practical rule that the expansion of steel is oneten-thousandth for every $15^{\circ} \mathrm{F}$., the jacket must be raised in temperature something over $150,000 \mathrm{~S} / 2 r_{i}$ degrees $\mathrm{Fahr}$.

Denoting by $u$ and $v$ the outward displacement of any circumferential fibre of the jacket or tube, of radius $r$ in the jacket and $\rho$ in the tube; then, since the tube and jacket fit closely at their common surface, or

$$
\begin{aligned}
& \rho_{o}+v_{0}=r_{i}+u_{i}, \\
& u_{i}-v_{o}=\rho_{o}-r_{i}=\frac{1}{2} \mathrm{~S} .
\end{aligned}
$$

(38) Supposing the tube and jacket to be both of steel of the same quality, so that $M$, the modulus of elasticity, is the same for both; and assuming that $R$ is uniform, then in the jacket $B$, from $(38)$,

$$
\mathrm{M} u_{i}=\left(t_{i}+\sigma p_{i}\right) r_{i}-\sigma \mathrm{R} r_{i},
$$

and in the tube $\mathbf{A}$,

$$
\mathrm{M} v_{o}=\left(-\tau_{0}+\sigma \widetilde{\omega}_{o}\right) \rho_{o}-\sigma \mathrm{R} \rho_{o} ;
$$

and now, since $p_{i}=\widetilde{\omega}_{o}$, and we may put $r_{i}=\rho_{o}$, subtraction gives-

or

$$
\begin{aligned}
\mathbf{M}\left(u_{i}-v_{0}\right) & =\left(t_{i}+\tau_{0}\right) r_{i}, \\
\mathrm{~S} & =\left(t_{i}+\tau_{0}\right) 2 r_{i} / \mathrm{M} ; \ldots . .(39)
\end{aligned}
$$

and $t_{i}$ and $\tau_{0}$ having been determined either from the formulas (6) to (I6), or graphically from Fig. 3, from the given value of $p_{i}=\widetilde{\omega}_{o}$, the requisite value is determined of the shrinkage $\mathrm{S}$, or of $\mathrm{S} / 2 r_{i}=\left(t_{i}+\tau_{v}\right) / \mathrm{M}$, which is the shrinkage, estimated as a fraction of the diameter.

This formula shows us that the shrinkage $S$ is the elongation or contraction which would be produced in a bar of steel, one square inch in section, and equal in length to the diameter $2 r_{i}$, by a pull or thrust of $t_{i}+\tau_{0}$ tons.

If we had taken $g$ as uniform, we should find in a similar manner-

$$
\mathrm{S}=\left(\mathbf{1}-\sigma^{2}\right)\left(t_{i}+\tau_{0}\right) 2 r_{i} \text { M. . . . (40) }
$$

With steel, $\sigma=\frac{1}{4}$ about, so that $\sigma^{\prime}=\frac{1}{3}$; and the values of the shrinkage calculated on the two assumptions of uniform $k$ and uniform $g$, would be in the ratio of $I$ to $I-\sigma^{2}$, or as $I 6$ to 15 ; thus differing by about 6 per cent., a difference which is practically insensible.

(39) In the numerical example we have given of the initial stresses of the tube and jacket, $t_{i}=5, \tau_{o}=5$; so that $\mathrm{S} / 2 r_{i}=$ IO/M.

For gun steel $\mathrm{M}=\mathbf{1 2}, 600$ about (Unwin, "Testing of Materials of Construction," p. 249); and supposing the tube and jacket to represent a 3 -inch field gun, $2 r_{i}=0$; and then

$$
\mathrm{S}=\mathrm{I} / 2 \mathrm{IO}=0.00476,
$$

4.76 thousands of an inch.

(40) In heavy guns, one or more hoops are shrunk on over the jacket; for instance, in the I IO-ton gun, three such series are superposed. Diagrams in section of modern guns will be found in recent numbers of the Engineer and of Engineering. 
The addition of each hoop that is shrunk on modifies the initial stresses previously existing. The annexed diagram (Fig. 7), taken from the American "Notes on the Construction of Ordnance," Nos. 3I, 33, 35, by Lieutenant Rogers Birnie, shows the shrinkage (enlarged 50 times) of the different parts, and the intermediate and final arrangements when a jacket, $B$, an inner hoop, C, and an outer hoop, D, are successively shrunk on the tube A of the American 8-inch gun, shown in longitudinal section in Fig. 8.

But knowing the initial stresses in the gun, as determined in the manner already explained in Part I., we can determine the requisite shrinkage at each common surface, for any number of layers, by a formula as simple as that just found for the tube $A$ and jacket $\mathrm{B}$, if only we assume that $\mathrm{M}$, the modulus of elasticity, is the same throughout.
(4I) Denote, as before, by $p_{m}$, the radial pressure at the radius, $r_{m}$, of the common surface of the $m$ th and $m+\mathbf{I t h}$ hoops, as reckoned from the interior; and by $t^{\prime} m, t_{m}$ the circum. ferential tensions at the exterior radius, $r_{m}$, of the $m$ th hoo $p$, and at the interior radius, $r_{m}$, of the $m+$ Ith hoop.

Denote also by $u_{m}^{\prime}, u_{m}$, the outward radial displacement from the unstrained position of the outer surface of the $m$ th hoop, and of the inner surface of the $m+$ Ith hoop.

Then, with uniform $\mathrm{R}$, from (38),

$$
\begin{aligned}
\mathrm{M} u_{m} & =\left(t_{m}+\sigma p_{m}\right) r_{m}-\sigma \mathrm{R} r_{m}, \\
\mathrm{M} u_{m}^{\prime} & =\left(t_{m}^{\prime}+\sigma p_{m}\right) r_{m}-\sigma \mathrm{R} r_{m} ; \\
\mathrm{M}\left(u_{m}-u_{m}^{\prime}\right) & =\left(\dot{t}_{m}-t_{m}^{\prime}\right) r_{m} .
\end{aligned}
$$

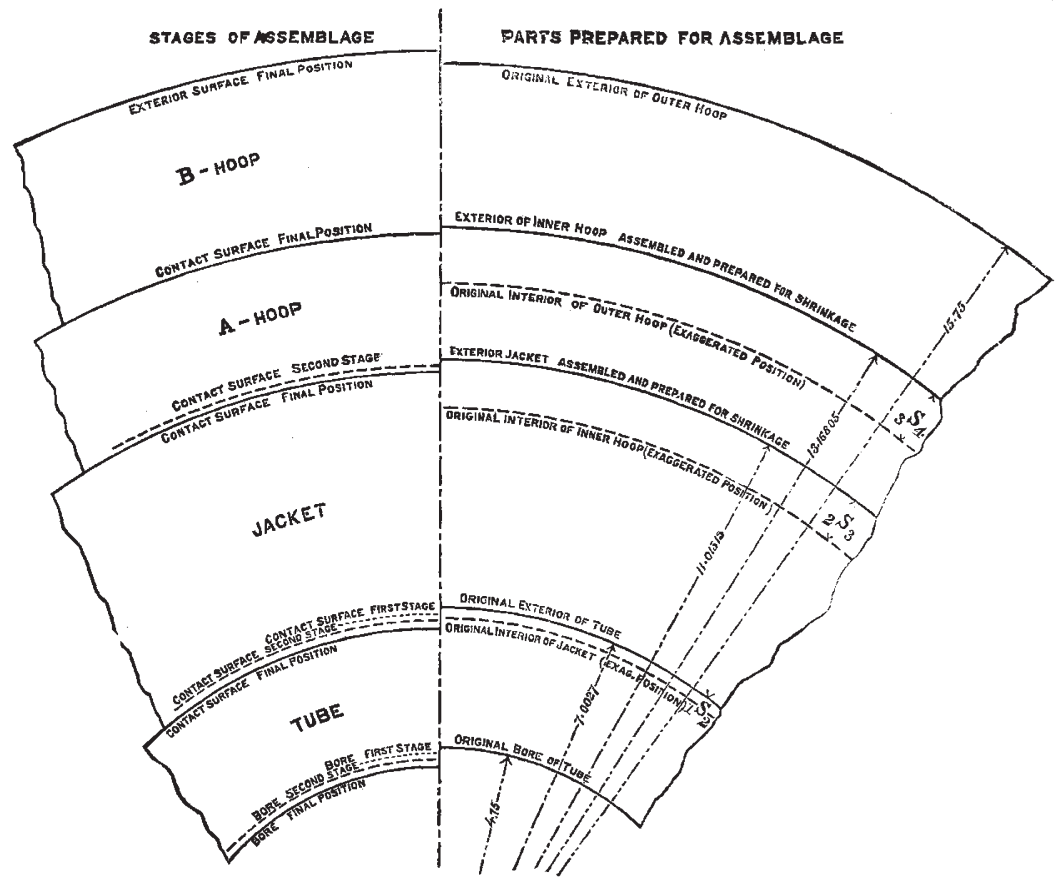

FIG. 7 .

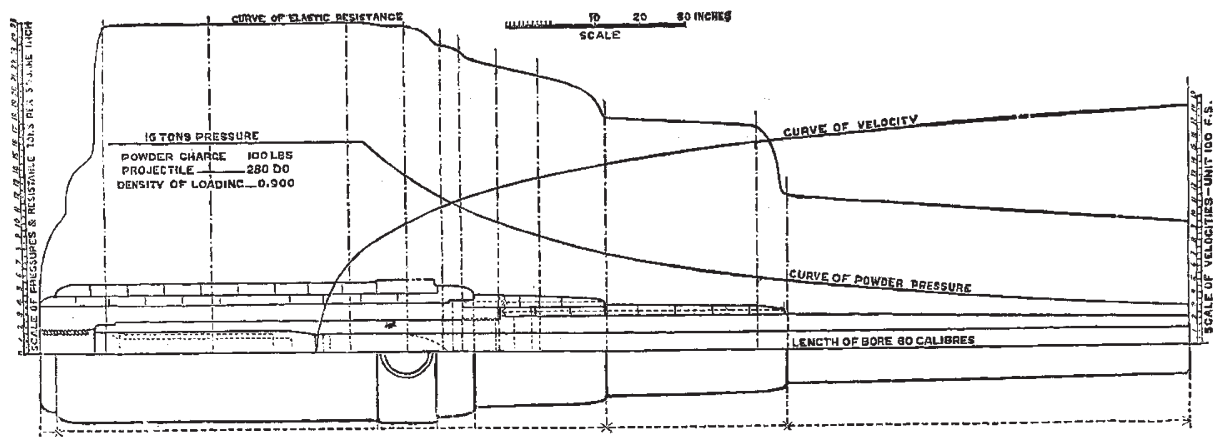

FIG. 8.

ow, using the notation $\mathrm{S}_{m+1}$ to denote the shrinkage when unstrained between the $m$ th and $m+$ ith hoops,

$$
\begin{aligned}
{ }_{m} \mathrm{~S}_{m+1} & =2\left(u_{m}-u_{m}^{\prime}\right) \\
& =\left(t_{m}-t_{m}^{\prime}\right) 2 r_{m} / \mathrm{M}, \ldots .
\end{aligned}
$$

the same as for a single tube, A, and jacket, B ; and showing that the shrinkage, ${ }_{m} \mathrm{~S}_{m+1}$, is the elongation or contraction which would be produced in a bar of steel, of modulus of elasticity M, one square inch in section, and of length equal to the diameter
$2 r_{m}$, by a pull or thrust of $t_{m}-t_{m}^{\prime}$ tons. On the assumption of uniform $g$, we should find-

$$
{ }_{m} \mathrm{~S}_{m+1}=\left(\mathbf{I}-\sigma^{2}\right)\left(t_{m}-t_{m}^{\prime}\right) 2 r_{m} / \mathbf{M}, \ldots .
$$

practically the same as for uniform $\mathbf{R}$.

(42) The stress formulas in the $m$ th hoop give-

$$
\begin{aligned}
& 2 a_{m}=\left(p_{m}+t_{m}^{\prime}\right) r_{m}^{2}=\left(p_{m}-+t_{m-1}\right) r_{m-1}^{2} . \\
& 2 b_{m}=\left(p_{m}-t_{m}^{\prime}=p_{m-1}-t_{m-1}\right.
\end{aligned}
$$

so that

$$
t_{m}-t_{m}^{\prime}=\left(t_{m}-t_{m-1}\right)-\left(p_{m}-p_{m-1}\right) \text {. }
$$

NO. IO83, VOL. 42] 
These values of $t_{m}$ and $t_{m}^{\prime}$ are the initial stresses or circum. erential tensions ; and as the powder pressure $p_{0}$ increases them by equal amounts, their difference is unaltered; so that $t_{m}-t_{m}^{\prime}$ is the same for the initial stresses or the firing stresses; and we may calculate the shrinkage, $S$, by the above formula from the values of the firing stresses, or of the initial stresses; the former being chosen, as given more directly when the maximum allowable tensions, represented by $t_{m}$, are given.

(43) As a numerical illustration, let us calculate the shrinkages in the American 8-inch gun, taking the previous results of $\S \mathbf{2 2}$, and $\mathrm{M}=\mathrm{I} 2,600$ (tons per square inch) for all the coils.

Then the final contraction of the bore

$$
{ }_{0} \mathrm{~S}_{1}=t_{0} \times 2 r_{0} \div \mathrm{M}=19^{\circ} 9 \times \text { 10 } \div \mathrm{I} 2,600=0.016,
$$

or 16 thousandths of an inch; and similarly,

$$
\begin{aligned}
& { }_{1} \mathrm{~S}_{2}=12.7 \times \mathrm{I} 4 \div \mathrm{I} 2,600=0.014 ; \\
& { }_{2} \mathrm{~S}_{3}=10.7 \times 22 \div \mathrm{I} 2,600=0.019 ; \\
& { }_{3} \mathrm{~S}_{4}=3.6 \times 26 \div \mathrm{M}=0.007 ; \\
& { }_{4} \mathrm{~S}_{5}=8 . \mathrm{I} \times 32 \div \mathrm{M}=0.02 \mathrm{I},
\end{aligned}
$$

the elongation of the external diameter of the last coil.

Lieutenant Rogers Birnie, following Clavarino ("Note on the Construction of Ordnance," No. 6), calls the extension or compression the relative elongation or relative contraction; so that the above values of ${ }_{0} \mathrm{~S}_{1},{ }_{1} \mathrm{~S}_{9},{ }_{2} \mathrm{~S}_{3},{ }_{3} \mathrm{~S}_{4},{ }_{4} \mathrm{~S}_{5}$, must be divided by $10,14,22,26,32$, to obtain his values of the relative elongation or contraction; and then, by $\S 37,150$ thousand times the relative elongation or contraction is the number of degrees Fahrenheit a jacket or coil must be raised in temperature to be expanded sufficiently so as to slip over the inner cylinders.

A. G. Greenhill.

\section{( To be continued.)}

\section{THE TOKIO TECHNICAL SCHOOL.}

THE Fapan Weekly Mail in a recent article describes the Tokio Technological School, situated at Asakusa, a suburb of that city. The inclosure in which the school buildings stand formerly belonged to the Shôgun's Government, and was used for the storage of rice. Several of its storehouses, which were ranged round a creek or blind canal leading off the river, still remain, and are utilized by the institution. A frame building of two stories, the chief modern portion, faces the roadway and runs at right angles to the creek. Here are the offices, showrooms, and lecture-rooms; the workshops are to be found between this building and the river. There are two great departments in the school, the Technological and the Mechanical. Of these the former is the more varied and interesting. To it are attached a dyeing shop, porcelain and glass furnaces, and technological laboratories; to the mechanical department are attached a drawing office, a pattern shop, and a foundry.

The history of the school begins with its foundation in $\mathbf{1 8 8 2}$, for the purpose of training foremen and managers for manufactories, and instructors for industrial schools. It was intended that the course of instruction should include all branches of industrial education concerned with arts and manufactures. The course was to extend over three and a half years, of which the first year should be devoted to general preparatory instruction and the others to special training in some particular branch. Next year certain alterations were made, making the course one of four years, and raising the standard. In August of that year the first batch of students, numbering sixty in all, were admitted. The school was shortly afterwards brought into connection with the Imperial University, and placed under the control of that institution-a step which led to a complete change in its curriculum. The preparatory course was abolished, and a short complete course, extending over two years, was instituted. Again, in 1888, a new Imperial decree severed its connection with the University, and placed it under the direct control of the Education Department. The school set itself anew to remodel its course of instruction, abolishing the short general course and resuming the course of three years; and elective courses were established with the view of making the school more popular and generally useful to mechanics and craftsmen. The laboratories and workshops are each provided with NO. 1083 , VOL. 42$]$ responsible superintendents, foremen, and assistants. The general direction is in the hands of a Committee, consisting of the manager of the school, two officials of the Education Department, and two officials of the Department of Agriculture and Commerce. Candidates for entrance to the regular courses must be not under seventeen nor over twenty-five years of age, and unless they have passed satisfactorily through a normal or middle school, must undergo an examination in Japanese, arithmetic, algebra and geometry, physics and chemistry, and English translation. Students sent up by local governments need not undergo this examination. The elective courses have been instituted for the benefit of artisans and mechanics, who, having no general scientific training, are anxious to study some part of the regular course. These candidates receive this privilege only when the convenience of the school admits of it, and are allowed to study for two years, taking one or more of the subjects immediately connected with their special crafts. An elective student must be at least seventeen years of age, and must have followed, for more than one year, some trade having special relation to the subjects of instruction which he has chosen. The fee paid by these students is about $3 s$. monthly.

In the mechanical engineering section-boilers, steam-engines, force-pumps-these last happen now to be in great demand in Japan as an improvement on the clumsy. well-bucket-and sawing-machines are manufactured. The shop is also prepared to execute orders for steam and hot-water heating apparatus, and has already fitted up the new Engineering College in the University grounds with a complete set of hot-water pipes and fittings. All the casting and founding required by the College are carried out at the Asakusa School. An improved pattern of perforating machine, now in use at the Imperial Printing Office, is also turned out. It is claimed for this pattern that it possesses a superiority over the one in common use in Europe for perforating stamps and other paper. Experiments are likewise in process on printing-presses, with the view of perfecting a machine for native use. The dyeing department is chiefly concerned with practical instruction in the best methods of fixing colours, rather than in any more original researches. Of late years the importation into Japan of aniline dyes has increased to such an extent that the total annual value of these imports now exceeds $£ 35$, 000 . Unfortunately, although these colours are very attractive to buyers, their proper use is still little understood. Silk, cotton, and other fabrics which have been coloured by native dyers do not wash well, and half the imported dye-stuffs run to waste. It is one of the chief aims of the instructors in this department to teach artisan how to fix these colours. Just now the school dye-shop is busying itself with this particular branch, and also with a series of experiments on the dyeing of mountain silk. This silk, which is soft in texture and durable in wear, refuses the ordinary dye, a. circumstance attributable to the presence in it of a largeamount of calcium carbonate. The pottery and glass depart ment is associated with the name of Dr. Wagner, who has for a long series of years enjoyed the confidence of the Japanese Government. Dr. Wagner is admitted to be the best authority on all matters connected with Japanese technology, and has directed his particular attention to the fabrication of a ware known in Japan as asahi-yaki, and elsewhere as Dr. Wagner's faience. Unlike the Satsuma, which is also faience, but of a much harder kind, this ware receives its decoration when in its unglazed state, which is a manifest advantage. It is made chiefly from a clay found in the Enya district of the Tochigi prefecture, with slight admixture of clays from other localities. The colour of the faience when baked varies from white, having a warm brown tinge, to lightish pink. Much of the asalii-yaki is exported to Germany and to the United States, and a certain amount to France, but little or none finds its way to Great Britain. Artists are at work on the spot decorating the plates and other articles preparatory to the receiving of the glaze. The object which Dr. Wagner and his colleagues have in view is technological and not artistic, and consists in perfecting native potters in the manipulation of the material

\section{SCIENTIFIC SERIALS.}

THE Quarterly Fournal of Microscopical Science for June I 890 contains :-On the embryology of a scorpion (Euscorpius italicus), by Malcolm Laurie (Plates xiii.-xviii.). The develop- 